\title{
Preparation and characterization of low-molecular-weight heparin/protamine nanoparticles (LMW-H/P NPs) as FGF-2 carrier
}

This article was published in the following Dove Press journal:

International Journal of Nanomedicine

10 March 2010

Number of times this article has been viewed

\section{Yasutaka Mori ${ }^{1,3,4}$ \\ Shingo Nakamura ${ }^{2}$ \\ Satoko Kishimoto' \\ Mitsuyuki Kawakami ${ }^{4}$ \\ Satoshi Suzuki ${ }^{4}$ \\ Takemi Matsui ${ }^{4}$ \\ Masayuki Ishihara'}

'Research Institute, ${ }^{2}$ Department of Surgery, National Defense Medical College, Tokorozawa, Saitama, Japan; ${ }^{3}$ Aeromedical Laboratory, Japan Air Self-Defense Force, Sayama, Saitama, Japan; ${ }^{4}$ Faculty of System Design, Tokyo Metropolitan University, Hino, Tokyo, Japan
Correspondence: Masayuki Ishihara Research Institute, National Defense Medical College, 3-2 Namiki, Tokorozawa, Saitama, 359-85।3, Japan

Tel +8I 429951618

Fax +8| $4299|16| 1$

Email ishihara@ndmc.ac.jp
Abstract: We produced low-molecular-weight heparin/protamine nanoparticles (LMW-H/P NPs) as a carrier for heparin-binding growth factors, such as fibroblast growth factor-2 (FGF-2). A mixture of low-molecular-weight heparin (MW: about $5000 \mathrm{Da}, 6.4 \mathrm{mg} / \mathrm{mL}$ ) and protamine (MW: about $3000 \mathrm{Da}, 10 \mathrm{mg} / \mathrm{mL}$ ) at a ratio of 7:3 (vol:vol) yields a dispersion of microparticles (1-6 $\mu \mathrm{m}$ in diameter). In this study, diluted low-molecular-weight heparin solution in saline $(0.32 \mathrm{mg} / \mathrm{mL})$ mixed with diluted protamine $(0.5 \mathrm{mg} / \mathrm{mL})$ at a ratio at $7: 3$ (vol:vol) resulted in soluble nanoparticles $(112.5 \pm 46.1 \mathrm{~nm}$ in diameter). The generated NPs could be then stabilized by adding $2 \mathrm{mg} / \mathrm{mL}$ dextran (MW: 178-217 kDa) and remained soluble after lyophilization of dialyzed LMW-H/P NP solution. We then evaluated the capacity of LMW-H/P NPs to protect activity of FGF-2. Interaction between FGF-2 and LMW-H/P NPs substantially prolonged the biological half-life of FGF-2. Furthermore, FGF-2 molecules were protected from inactivation by heat and proteolysis in the presence of LMW-H/P NPs.

Keywords: polyelectrolyte complexes, nanoparticles, fibroblast growth factor-2, drug carrier

\section{Introduction}

Polyelectrolyte complexes (PECs) are the products of electrostatic interaction between oppositely charged polyelectrolytes. Nonstoichiometric PECs are composed of oppositely charged polyions taken in nonequivalent ratios. As a result, each PEC particle carries an excess charge. ${ }^{1,2}$ PECs are convenient models for studying the in vivo behavior of charged biopolymers. The attractive combination of a simple preparation procedure and unique properties offer various possible applications of PECs in medicine and biotechnology. ${ }^{3,4}$ Proteins interact with both synthetic and natural polyelectrolytes. ${ }^{5,6}$ Some evidences exist for the binding of polyanions and polycations to proteins below and above their isoelectric points, respectively. These interactions can result in soluble complexes, complex coacervation and/or the formation of amorphous precipitates. ${ }^{4-6}$ Main aspects studied by different authors are compositions of PECs obtained under various experimental conditions, such as the strength and position of ionic sites, charge density, and rigidity of polymer chains, as well as chemical properties such as solubility, $\mathrm{pH}$, temperature, and concentration. ${ }^{1-4}$

An interest in such electrostatic interactions lies in their similarity to biological systems $;{ }^{7}$ such interactions between proteins and nucleic acids very likely play a role in the transcription process. ${ }^{5}$ DNA/chitosan PECs,${ }^{8}$ chiosan/chondroitin sulfate PECs and chitosan/hyaluronate PECs ${ }^{9}$ have been reported as gene and 
drug carriers. Moreover, PECs which are insoluble, also have potential applications as, for example, membranes, microcapsules, micro (nano)-particles and scaffolds for tissue engineering. ${ }^{10}$

Heparinoids are known to specifically interact with variety of functional proteins, including growth factors, cytokines, extracellular matrix components and adhesion molecules. ${ }^{11-13}$ Thus, heparin may be useful as a therapeutic agent in various pathological conditions involving functional proteins. However, high-dose heparin cannot be used because of the excessive risk of bleeding. ${ }^{14}$ In contrast, low-molecular-weight heparin (LMW-H, MW: about $5000 \mathrm{Da}$ ) has pharmacological and practical advantages when compared with heparin. The lower protein binding activity of LMW-H produces a low, stable and predictable anticoagulant response, thereby obviating the need for laboratory monitoring to adjust the dosage. ${ }^{14}$ In addition, one or two subcutaneous injections per day are sufficient to maintain therapeutic concentrations, due to its longer plasma half-life. ${ }^{14}$

On the other hand, protamine, a purified mixture of proteins obtained from fish sperm, neutralizes heparin and LMW-H by forming a stable complex that lacks anticoagulant activity. ${ }^{15}$ Protamine is also in clinical use to reverse the anticoagulant activity of heparin following cardiopulmonary bypass and in cases of heparin-induced bleeding. ${ }^{16} \mathrm{We}$ previously prepared water-insoluble particles $(>10 \mu \mathrm{m}$ in diameter) by mixing nonanticoagulant heparin and chitosan and by mixing of fucoidan and chitosan, and investigated the capacity of the resulting insoluble fucoidan/chitosan microparticles to protect activity of fibroblast growth factor-2 (FGF-2). ${ }^{17,18}$ We also prepared water-insoluble microparticles $(>1 \mu \mathrm{m}$ in diameter) by mixing LMW-H $(6.4 \mathrm{mg} / \mathrm{mL})$ and protamine $(10 \mathrm{mg} / \mathrm{mL})$ at a ratio of $7: 3$ (vol:vol), and investigated the capacity of the resulting injectable LMW$\mathrm{H} /$ protamine microparticles (LMW-H/P MPs) to protect the activity of FGF-2. ${ }^{19}$ However, after the LMW-H/P MPs were freeze-dried, a cotton-like amorphous material was generated, and this was not dissolved with water. In this study, we used diluted LMW-H $(\leq 0.32 \mathrm{mg} / \mathrm{ml})$ as an anion molecule and the diluted protamine as a cation molecule to synthesize LMW$\mathrm{H} /$ protamine nanoparticles (LMW-H/P NPs; about $120 \mathrm{~nm}$ in diameter). Although the LMW-H/P NPs were also freezedried, cotton-like amorphous materials were generated, and these were not dissolved with water, the generated LMW-H/P NPs as well as LMW-H/P MPs were then stabilized by adding dextran. Here, we report that LMW-H/P NPs are able to interact with FGF-2 and to protect FGF-2 activity from heat and proteolytic inactivation.

\section{Material and methods Preparation of LMW-H/P NPs and LMW-H/P MPs}

LMW-H/P MPs were prepared as reported elsewhere. ${ }^{19}$ Briefly, $0.3 \mathrm{~mL}$ of protamine solution $(10 \mathrm{mg} / \mathrm{mL}$; Mochida Pharmaceutical Co., Ltd., Tokyo, Japan) was drop by drop added to $0.7 \mathrm{~mL}$ of LMW-H solution (Fragmin ${ }^{\circledR}, 6.4 \mathrm{mg} / \mathrm{mL}$; Kissei Pharmaceutical Co., Ltd., Nagano, Japan) with vortexing for approximately $2 \mathrm{~min}$. To maximize the production of microparticles, LMW-H and protamine were mixed at a ratio at 7:3 (vol:vol). The solution of LMW-H/P MPs ( $1 \mathrm{~mL})$ was then subjected to washing twice with phosphate-buffered saline (PBS) to remove unreacted materials, and was made up with $1 \mathrm{ml}$ of PBS. More than $7 \mathrm{mg}$ of freeze-dried LMW-H/P MPs was obtained from $1 \mathrm{ml}$ of the LMW-H/P MP solution, and the dried LMW-H/P MPs were substantially aggregated and insoluble cotton-like materials were generated in the resuspended freeze-dried LMW-H/P MPs. However, addition of $5 \mathrm{mg} / \mathrm{mL}$ dextran prevented such aggregation.

In order to prepare LMW-H/P NPs, $30 \mathrm{ml}$ of 20 -fold diluted protamine solution $(0.50 \mathrm{mg} / \mathrm{ml})$ in saline (Otsuka Pharmaceutical Co. Ltd., Tokyo, Japan) was drop by drop added to $70 \mathrm{ml}$ of 20 -fold diluted LMW-H solution $(0.32 \mathrm{mg} / \mathrm{ml})$ in saline with stirring. The solution $(100 \mathrm{ml})$ was mixed with $200 \mathrm{mg}$ of dextran (MW: 178-217 kDa; MRC Polysaccharide Corp., Tokyo, Japan) and was then dialyzed for 3 days against distilled water using a dialysis membrane (Seamless Cellulose Tubing; Fractional molecular weight: 12-14 kDa; Sanko Corp., Tokyo, Japan) in order to remove unreacted materials and salts, and the dialysate was lyophilized. The weight of lyophilized powder was $239 \mathrm{mg}$ including $200 \mathrm{mg}$ of dextran and the produced powder was resuspended in $20 \mathrm{ml}$ of PBS. Particle aggregation with addition of dextran was not observed, even in re-suspended freeze-dried LMW-H/P NP solution. As the concentration of LMW-H in the LMW-H /P NP solution was $0.82 \mathrm{mg} / \mathrm{mL}$ according to a sulfated glycosaminoglycan assay kit (Blyscan ${ }^{\mathrm{TM}}$; Biocolor Ltd., Newtownabbey, North Ireland), it was estimated that about $73 \%$ of LMW-H was converted into LMW-H/P NPs. If $100 \%$ of protamine was converted to LMW-H/P NPs, the final yield of LMW-H/P NPs was about $31.4 \mathrm{mg}$ in the $20 \mathrm{~mL}$ of LMW-H/P NP solution. In order to prepare stock solution for FGF-2 protection, $10 \mu \mathrm{L}$ of $1.0 \mathrm{mg} / \mathrm{mL}$ FGF-2 (Fiblast; Kaken Pharmaceutical Corp., Tokyo, Japan) in PBS (final concentration of FGF-2: $10 \mu \mathrm{g} / \mathrm{mL}$ ) was then added to $1 \mathrm{~mL}$ of the resuspended freeze-dried LMW-H/P $\mathrm{NP}(3.14 \mathrm{mg} / \mathrm{mL})$ and dextran $(20 \mathrm{mg} / \mathrm{mL})$ solution with 
medium-199 (Life Technologies Oriental Corp., Tokyo, Japan) containing antibiotics and lacking heat-inactivated fetal bovine serum (FBS) on ice, followed by vortexing.

\section{Scanning electron microscopy (SEM)}

SEM was carried out using a JEOL JSM-6340F (JEOL Ltd., Tokyo, Japan) at $5 \mathrm{kV}$. SEM specimens of LMW-H/P NPs (LMW-H/P MPs) were prepared by coating a cover glass with a drop of $5 \mu \mathrm{L}$ water dispersion of the perticles. The specimen was followed by gentle drying in a dry-box for overnight. To enhance conductivity of the specimen, osmium plasma coating was performed using the plasma multi-coater PMC-5000 (Meiwafosis Co., Ltd., Tokyo, Japan) after drying. Particle size distributions of LMW-H/P NPs and LMW-H/P MPs were measured in SEM images using LabVIEW (Version 8.5) with the Vision Development/Module (National Instrument Co., Austin, TX, USA). To obtain the average size and standard deviation of the particles, each particle images on the SEM micrographs were evaluated as circle with LabVIEW and the diameters of the relevant circles were used for the calculation. The number of the particles used for the calculation was more than 400 (for NPs) or 100 (for MPs).

\section{HMVEC culture and protection of FGF-2 from inactivation by LMW-H/P NPs}

Human dermal micro-vascular endothelial cells (HMVECs; Takara Biochemical Corp., Ohtsu, Japan) were cultured in medium-199 supplemented with $10 \mathrm{wt} \%$ FBS, antibiotics (100 U/mL penicillin $\mathrm{G}$ and $100 \mu \mathrm{g} / \mathrm{ml}$ streptomycin) and $5 \mathrm{ng} / \mathrm{mL}$ FGF-2. Those cells used in this work were all between the fourth and eighth cell cycle passage.

In order to study the effects of LMW-H/P NPs on inhibition of FGF-2 inactivation with various incubation times, $10 \mu \mathrm{g}$ of FGF-2 was added to $1 \mathrm{~mL}$ of medium-199 (Life Technologies Oriental Corp., Tokyo, Japan) without FBS containing $3.14 \mathrm{mg} / \mathrm{mL}$ LMW-H/P NPs (with $20 \mathrm{mg} / \mathrm{mL}$ dextran), $1.6 \mathrm{mg} / \mathrm{mL} \mathrm{LMW}-\mathrm{H}$ or $20 \mathrm{mg} / \mathrm{mL}$ dextran, and these solutions were thoroughly mixed as stock solutions. Stock solutions were directly incubated at $37^{\circ} \mathrm{C}$ for the indicated periods. For heat treatment of FGF-2, $0.1 \mathrm{~mL}$ of each stock solution was heated at $37,44,51,58,65$ and $72^{\circ} \mathrm{C}$ for $30 \mathrm{~min}$. To study the effects of trypsinization of FGF-2, $0.1 \mathrm{~mL}$ of trypsin-EDTA solution $(0.5 \mathrm{mg} / \mathrm{mL}$ trypsin, $0.2 \mathrm{mg} / \mathrm{mL}$ EDTA/4Na in HBSS; Sigma, St. Louis, MO, USA) was added to $0.1 \mathrm{~mL}$ of each chilled stock solution, followed by incubation at $37^{\circ} \mathrm{C}$ for the indicated periods. After incubation, $0.1 \mathrm{~mL}$ of FBS was added to each trypsinized stock solution in order to stop the trypsinization reaction.
Those inactivated FGF-2 stock solutions were diluted with medium-199 supplemented with 10\% FBS and antibiotics at the indicated concentrations, and the media were used for HMVEC culture. The HMVECs were seeded at an initial density of 3000 cells/well in 96-well tissue culture plates, and were grown for 3 days in $200 \mu \mathrm{L}$ of one of the prepared media. After incubation, the medium used was removed and $100 \mu \mathrm{L}$ of fresh medium including $10 \mu \mathrm{L}$ of WST- 1 reagent (Cell counting kit, Dojindo, Kumamoto, Japan) was added to each well. Plates were read at $450 \mathrm{~nm}$ using a Mini Plate Reader (Nunc InterMed, Tokyo, Japan) after $1 \mathrm{~h}$ incubation at $37^{\circ} \mathrm{C}$.

\section{Results}

\section{Appearance and characteristics of LMW- $\mathrm{H} / \mathrm{P}$ MPs produced by mixing LMW-H and protamine at various ratios}

When nondiluted protamine $(10 \mathrm{mg} / \mathrm{ml})$ was drop by drop added to nondiluted LMW-H $(6.4 \mathrm{mg} / \mathrm{mL})$ until 0.4 of the volume fraction, a gradual increase in turbidity was observed (Figure 1). Figure 2 shows that the high turbidity was due to the generated LMW-H/P MPs $(2.93 \pm 1.11 \mu \mathrm{m}$ in diameter $)$. Turbidity was measured by reading OD at $630 \mathrm{~nm}$ using a Mini Plate Reader (Nunc InterMed., Tokyo, Japan). When the volume fraction of protamine was low (0.10-0.15), the turbidity was also low. However, electron microscopic

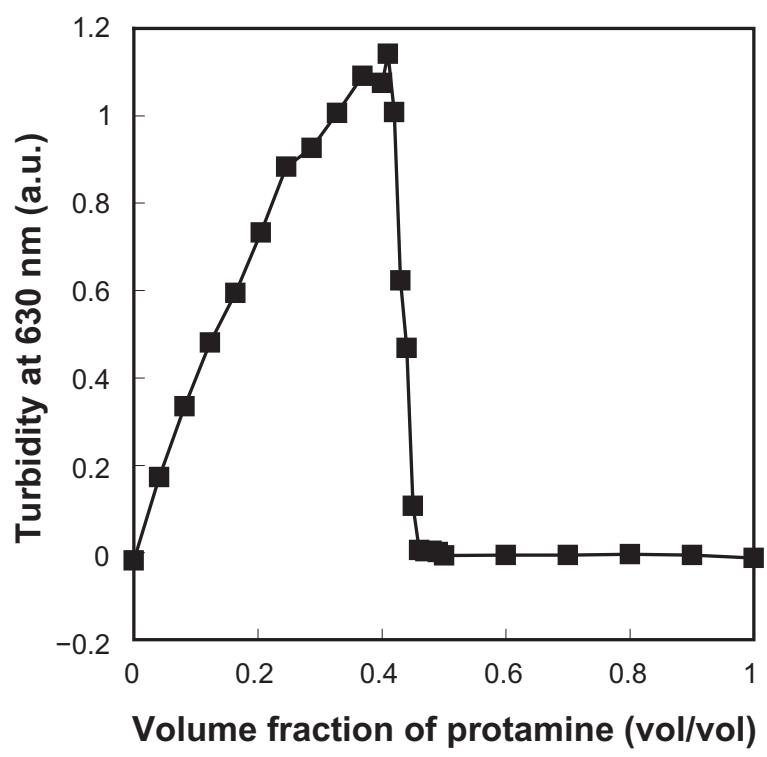

Figure I Changes in turbidity by mixing protamine to $\mathrm{LMW}-\mathrm{H}$ at various ratios. When protamine $(10 \mathrm{mg} / \mathrm{mL})$ was added dropwise to $\mathrm{LMW}-\mathrm{H}(6.4 \mathrm{mg} / \mathrm{mL})$ until 0.4 of the volume fraction, gradual increases in turbidity were observed. When the volume fraction of protamine was high $(>0.5)$, turbidity was very low due to generated insoluble oily precipitates.

Abbreviations: LMW-H, low-molecular-weight heparin. 

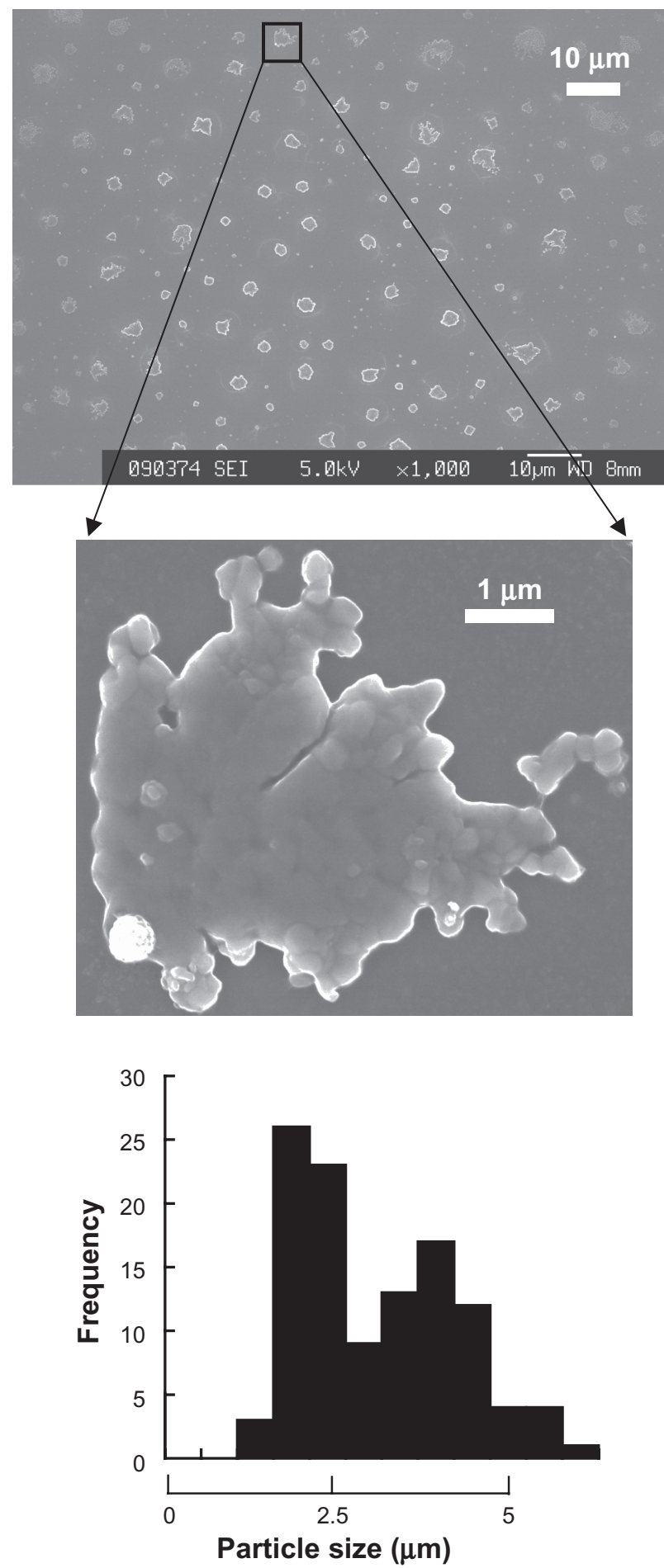

Figure $2 \mathrm{LMW}-\mathrm{H} / \mathrm{P} M P$ s produced by mixing protamine to $\mathrm{LMW}-\mathrm{H}$. LMW-H $(6.4 \mathrm{mg} / \mathrm{mL})$ and protamine $(10 \mathrm{mg} / \mathrm{mL})$ were mixed to produce $\mathrm{LMW}-\mathrm{H} / \mathrm{P}$ MPs at a ratio of 7:3 (vol:vol). Produced microparticles were aggregates composed of many nanoparticles and particle size was $2.93 \pm 1.11 \mu \mathrm{m}$.

Abbreviations: LMW-H, low-molecular-weight heparin; LMW-H/P, low-molecularweight heparin/protamine; MPs, microparticles.

observation confirmed the generation of LMW-H/P NPs (about $100 \mathrm{~nm}$ in diameter) and LMW-H/P MPs (about $1 \mu \mathrm{m}$ in diameter) (data not shown). Furthermore, when the volume fraction of protamine was high $(>0.5)$, insoluble oily precipitates were generated, and turbidity of the supernatant was almost zero (Figure 1). An illustration of the generation of micro/nanoparticles by mixing protamine $(10 \mathrm{mg} / \mathrm{mL})$ and LMW-H $(6.4 \mathrm{mg} / \mathrm{mL})$ at various volume ratios is shown in Figure 3. In contrast, when nondiluted LMW-H was drop by drop added to nondiluted protamine, insoluble oily precipitates were immediately generated. The reaction was irreversible, and the generation of micro/nanoparticles was not observed.

\section{Appearance and characteristics of LMW- $\mathrm{H} / \mathrm{P}$ NPs produced by mixing LMW-H and protamine at various concentrations}

In order to produce nanoparticles, equally diluted LMW-H and protamine (100-fold, 50-fold, and 20-fold diluted) were mixed at a ratio at 7:3 (vol:vol) (Figure 4). The diameters of LMW-H/P NPs generated by mixing 100-fold, 50-fold, and 20-fold diluted protamine to equally diluted LMW-H in a ratio of 3:7 (vol:vol) were 84.6 $\pm 26.8,95.0 \pm 27.0$, and $112.5 \pm 46.1 \mathrm{~nm}$, respectively, and no microparticles ( $>1 \mu \mathrm{m}$ in diameter) were observed in these mixtures. In contrast, a certain amount of microparticles (about $1 \mu \mathrm{m}$ in diameter) were observed when mixing 10-fold diluted protamine $(1.0 \mathrm{mg} / \mathrm{mL})$ with LMW-H $(0.64 \mathrm{mg} / \mathrm{mL})$ at a ratio of 3:7 (vol:vol). When nondiluted protamine (10 mg/ $\mathrm{mL})$ was added to nondiluted LMW-H $(6.4 \mathrm{mg} / \mathrm{mL})$ at a ratio of 3:7 (vol:vol), maximal LMW-H/P MPs (2.93 \pm $1.11 \mu \mathrm{m}$ in diameter) was produced and high turbidity was observed (Figure 1). When 10-fold concentrated protamine $(100 \mathrm{mg} / \mathrm{mL})$ was added to equally concentrated LMW-H $(64 \mathrm{mg} / \mathrm{mL})$ at a ratio of 3:7 (vol:vol), mixtures of LMW-H/P MPs and larger cotton-like precipitates were immediately generated and the products were insoluble (data not shown).

\section{Effects of dextran on resolubility after lyophilization}

Cotton-like compounds were generated after lyophilization of both LMW-H/P NP and LMW-H/P MP solutions (without dextran), and these were hardly re-soluble in water. However, both the freeze-dried LMW-H/P MPs and LMW-H/P NPs were easily dissolved in water by adding $0.5 \%$ and $0.2 \%$ dextran, respectively, before lyophilization. In addition, aggregation of LMW-H/P NPs and LMW-H/P MPs in solution was prohibited in the presence of dextran. Thus, addition of dextran stabilizes the LMW-H/P NPs and LMW-H/P MPs in solution, and allows preparations of stable and resoluble freeze-dried LMW-H/P MPs and LMW-H/P NPs. 


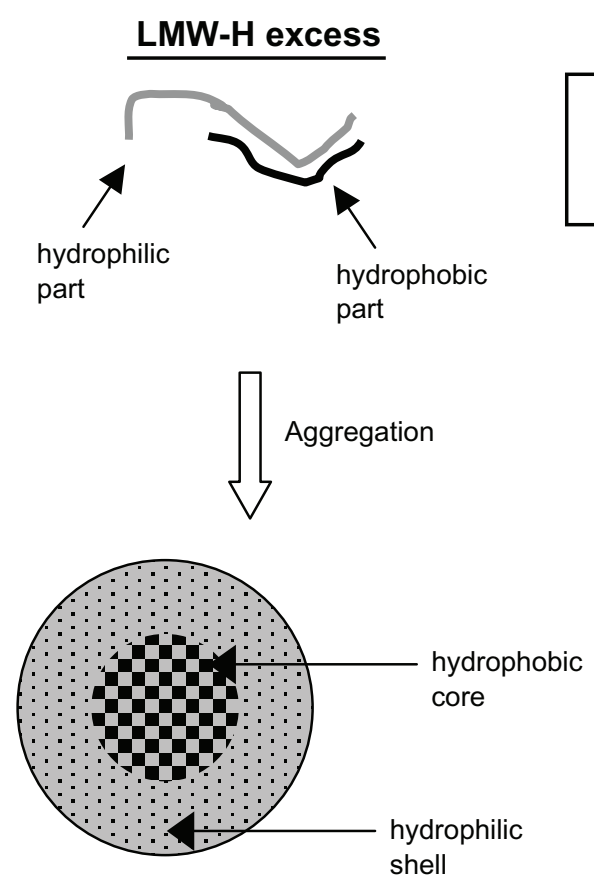

\section{Protamine excess}

: LMW-H

: Protamine

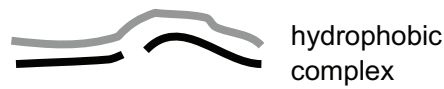

$\lceil$ Precipitation

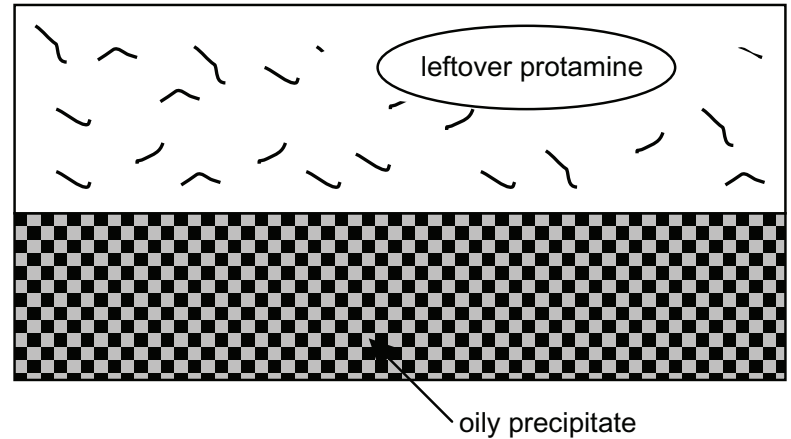

Figure 3 Illustration of LMW-H/P MP and LMW-H/P NP generation by mixing protamine to LMW-H at various ratios.

Abbreviations: LMW-H, low-molecular-weight heparin; LMW-H/P, low-molecular-weight heparin/protamine; MP, microparticle; NP, nanoparticle.

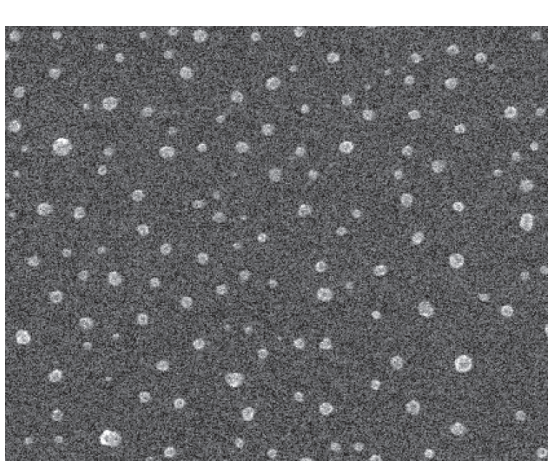

100-fold diluted

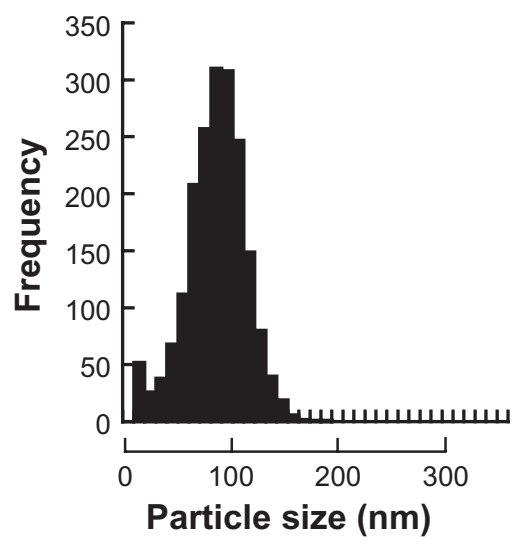

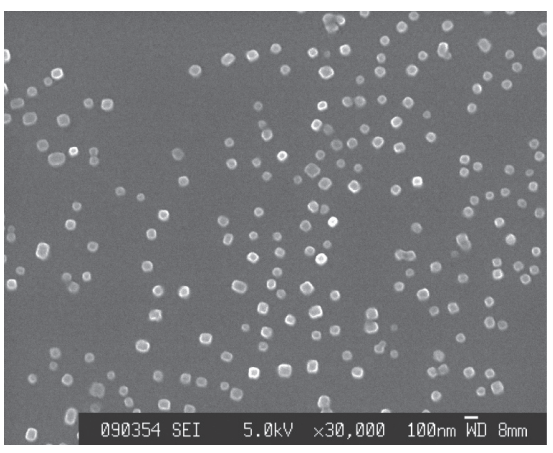

50 -fold diluted

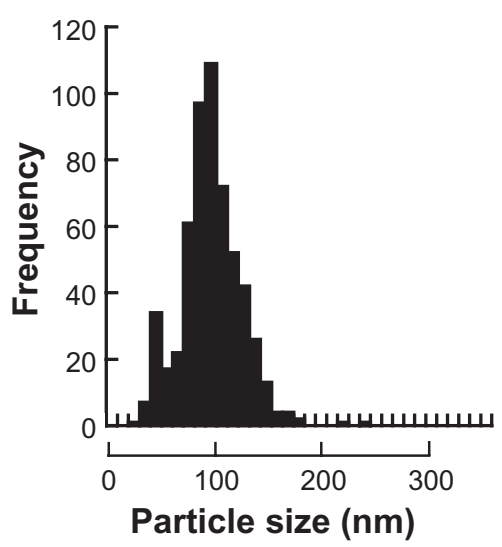

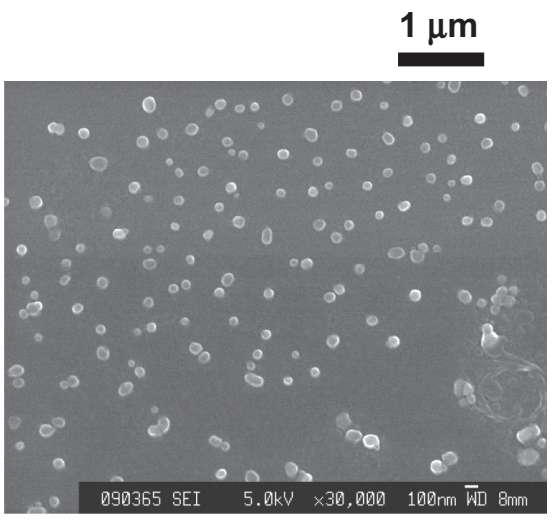

20-fold diluted

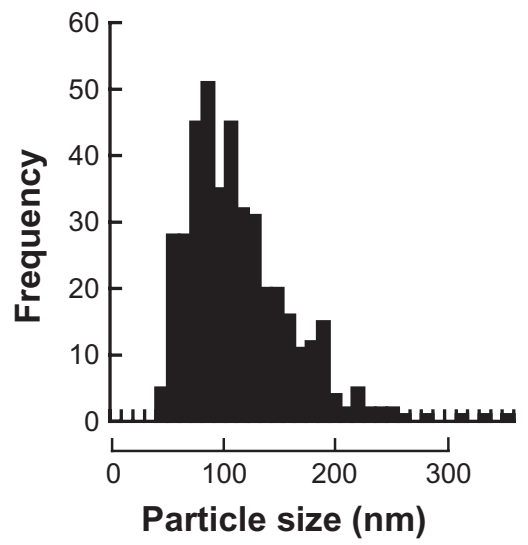

Figure $4 \mathrm{LMW}-\mathrm{H} / \mathrm{P}$ NPs produced by mixing diluted protamine and LMW-H. Equally diluted aqueous LMW-H solution and protamine solution were mixed at a ratio of 7:3 (vol:vol) to produce LMW-H/P NPs. Produced nanoparticles were PECs and nanoparticle size was $84.6 \pm 26.8$ and $95.0 \pm 27.0 \mathrm{~nm}$ after mixing 100 - and 50 -fold diluted protamine and LMW-H, respectively. When mixing 20-fold diluted protamine and LMW-H solutions, LMW-H/P NPs were generated and the size was II $2.5 \pm 46 . \mathrm{Imm}$. Abbreviations: LMW-H, low-molecular-weight heparin; LMW-H/P, low-molecular-weight heparin/protamine; NPs, nanoparticles; PECs, polyelectrolytes. 


\section{LMW-H/P NPs protect FGF-2}

\section{from inactivation}

When FGF-2 is incubated at $37^{\circ} \mathrm{C}$ for 1 day or more, its mitogenic activity is substantially reduced $(<90 \%)$, whereas no decrease in the mitogenic activity of FGF- 2 was observed in the presence of either $1.6 \mathrm{mg} / \mathrm{mL}$ LMW-H with $20 \mathrm{mg} / \mathrm{mL}$ dextran, $3.14 \mathrm{mg} / \mathrm{mL}$ LMW-H/P NPs with $20 \mathrm{mg} / \mathrm{mL}$ dextran, or $20 \mathrm{mg} / \mathrm{mL}$ dextran alone for at least 7 days (Figure 5). The biological half-life of $10 \mathrm{ng} / \mathrm{mL} \mathrm{FGF-2} \mathrm{in} \mathrm{the} \mathrm{presence} \mathrm{of}$

Day 0
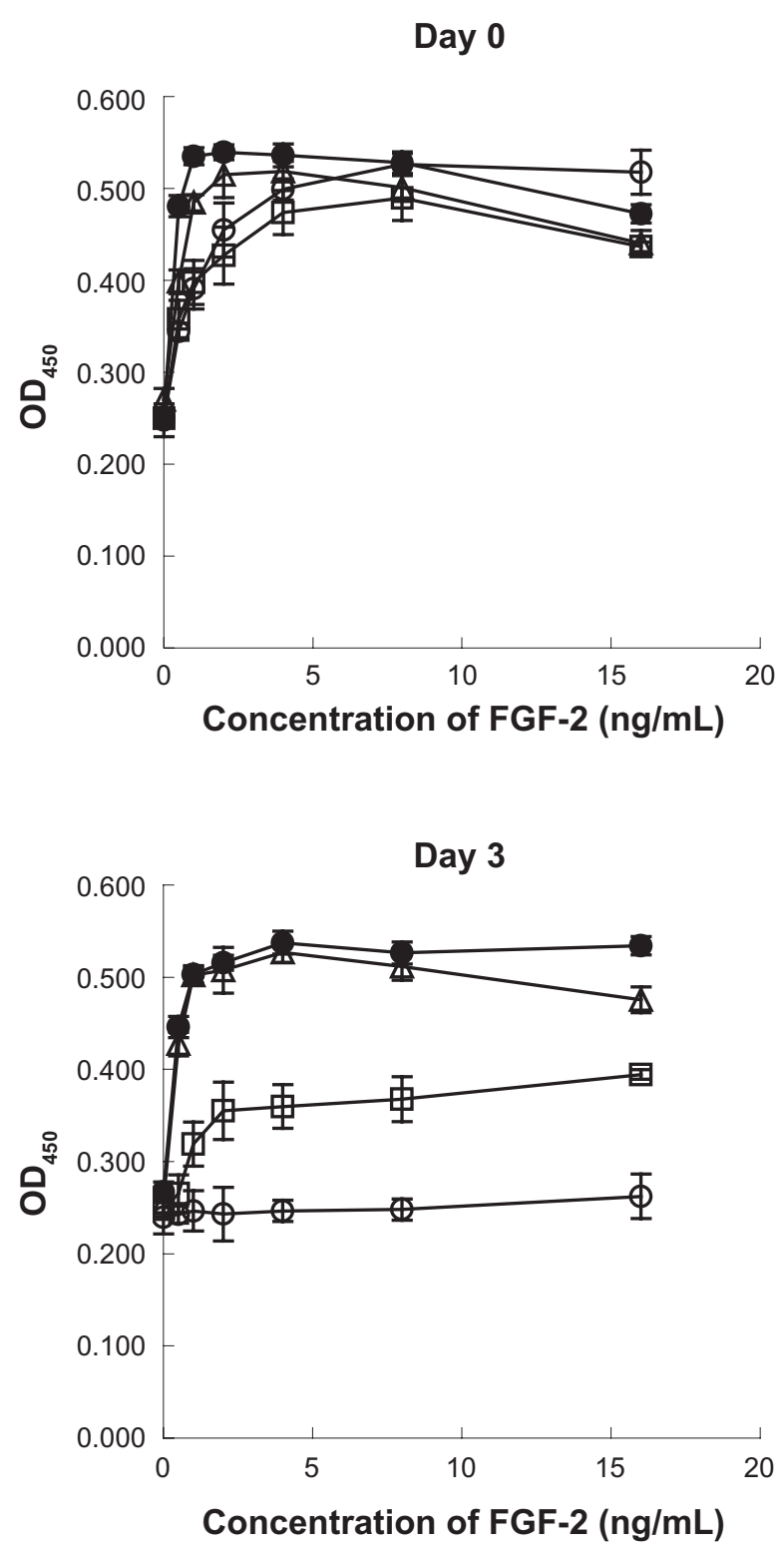

LMW-H/P NPs with dextran, LMW-H with dextran, dextran and control (non) was approximately $>7$ days, $>7$ days, 2 days, and $<1$ day, respectively.

Heparin protects FGF-2 from inactivating treatments by heat and proteolysis. ${ }^{19-21}$ To determine whether LMWH/P NPs with dextran could protect FGF-2 against heat inactivation, FGF-2 $(10 \mu \mathrm{g} / \mathrm{mL})$ was heated in the presence of LMW-H/P NPs $(3.14 \mathrm{mg} / \mathrm{mL})$. As shown in Figure 6, heat exposure at over $51{ }^{\circ} \mathrm{C}$ in the absence of LMW-H with
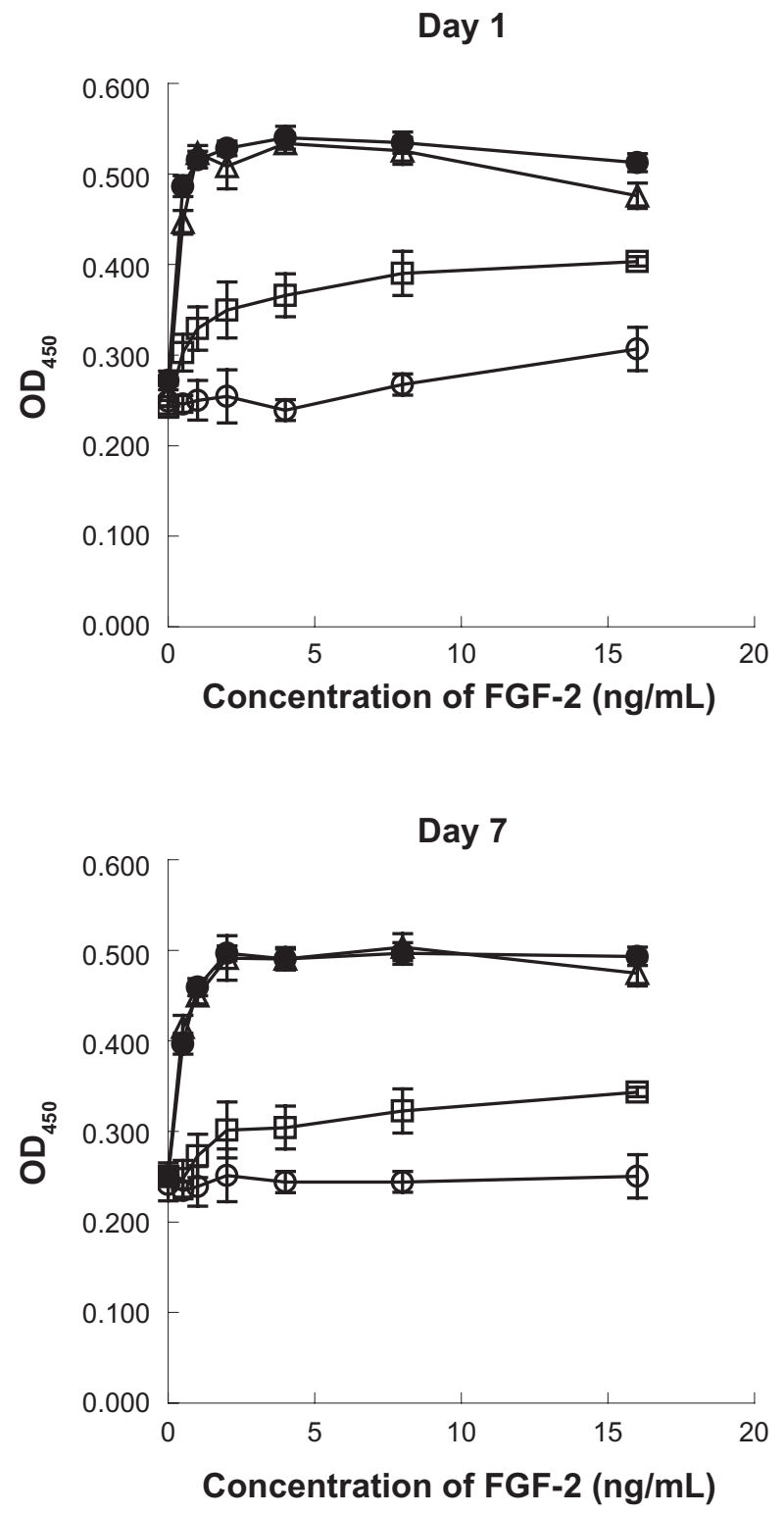

Figure 5 Protective effects of LMW-H/P NP on FGF-2 activity. Stock solutions ( $10 \mu \mathrm{gg} / \mathrm{ml} \mathrm{FGF-2} \mathrm{with} 3.14 \mathrm{mg} / \mathrm{mL} \mathrm{LMW}-\mathrm{H} / \mathrm{P} \mathrm{NPs}$ with $20 \mathrm{mg} / \mathrm{mL}$ dextran $(0)$, I.6 mg/mL LMW-H with $20 \mathrm{mg} / \mathrm{mL}$ dextran $(\triangle), 20 \mathrm{mg} / \mathrm{mL}$ dextran alone $(\square)$ or control (non) $(\bigcirc)$ ) were incubated at $37^{\circ} \mathrm{C}$ for 0 , I, 3 , and 7 days. FGF-2 in the stock solution was diluted to the indicated concentrations with culture medium. HMVECs were cultured for 3 days using one of the prepared media, and data represent means \pm SD of quadruplicate determinations.

Abbreviations: FGF-2, fibroblast growth factor-2; HMVECs, human dermal micro-vascular endothelial cells; LMW-H, low-molecular-weight heparin; LMW-H/P, low-molecularweight heparin/protamine; NP(s), nanoparticle(s); SD, standard deviation. 

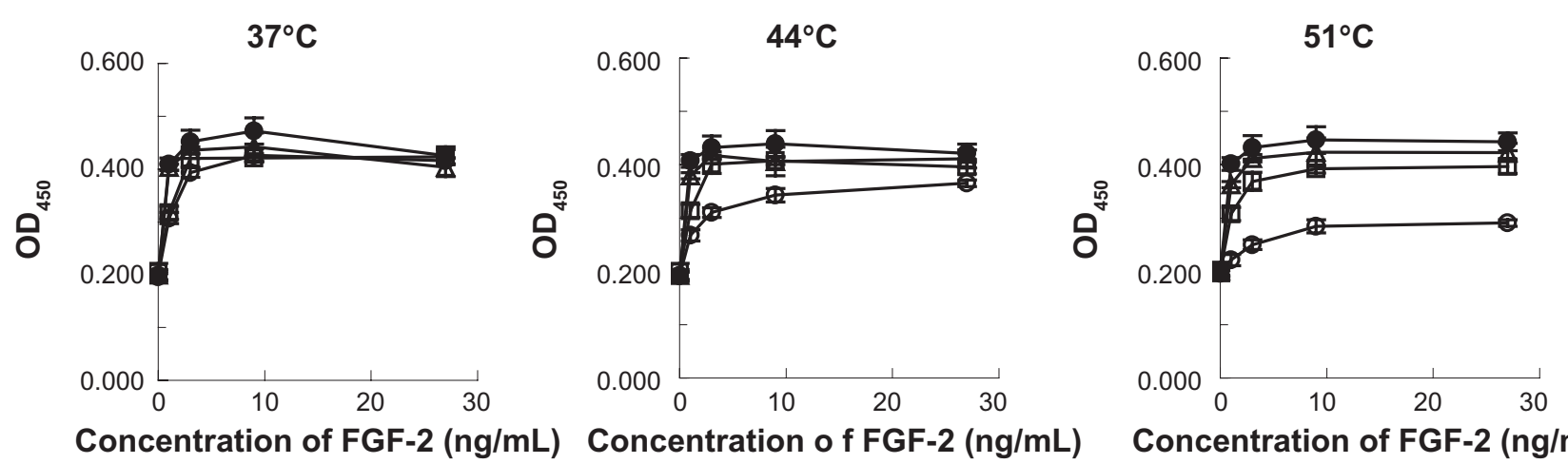

Concentration of FGF-2 $(\mathrm{ng} / \mathrm{mL})$ Concentration of FGF-2 $(\mathrm{ng} / \mathrm{mL})$

Concentration of FGF-2 $(\mathrm{ng} / \mathrm{mL})$
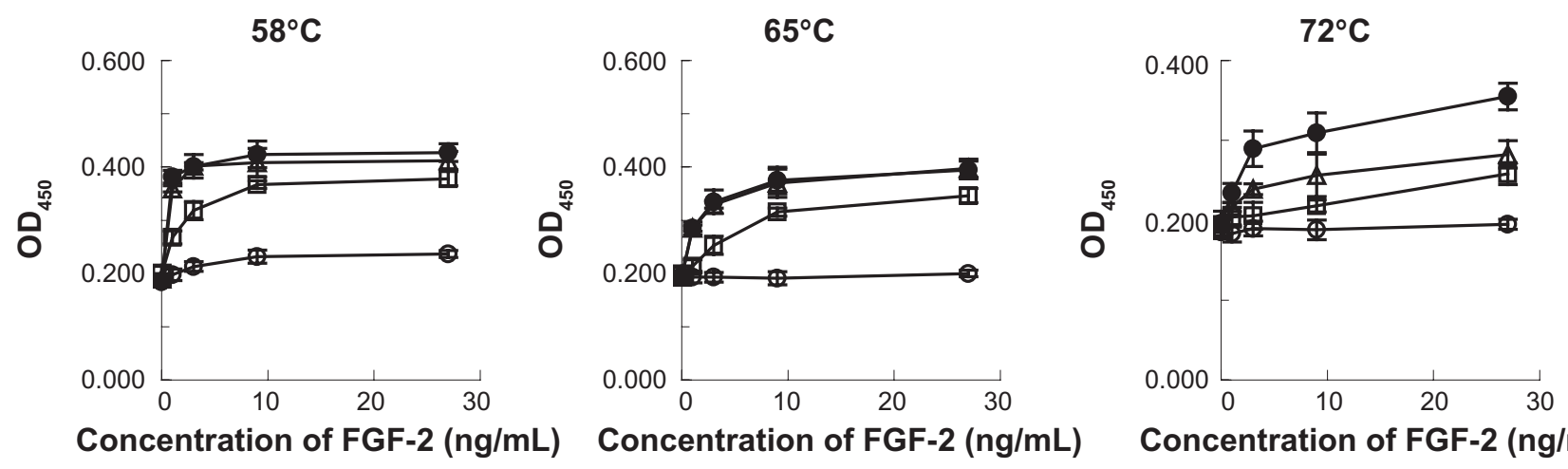

Concentration of FGF-2 $(\mathrm{ng} / \mathrm{mL})$ Concentration of FGF-2 $(\mathrm{ng} / \mathrm{mL})$

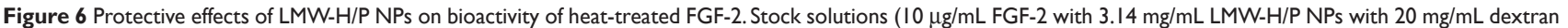
(๑), $1.6 \mathrm{mg} / \mathrm{mL} \mathrm{LMW-H}$ with $20 \mathrm{mg} / \mathrm{mL}$ dextran $(\triangle), 20 \mathrm{mg} / \mathrm{mL}$ dextran alone ( $\square$ ) or control (non) $(\bigcirc)$ ) were incubated at $37,44,51,58,65$ and $72^{\circ} \mathrm{C}$ for $30 \mathrm{~min}$. FGF-2 in the stock solution was diluted to the indicated concentrations with culture medium. HMVECs were cultured for 3 days using one of the prepared media, and data represent means \pm SD of quadruplicate determinations.

Abbreviations: FGF-2, fibroblast growth factor-2; HMVECs, human dermal micro-vascular endothelial cells; LMW-H, low-molecular-weight heparin; LMW-H/P, low-molecularweight heparin/protamine; NP(s), nanoparticle(s); SD, standard deviation.

dextran, dextran or LMW-H/P NPs with dextran resulted in more than $95 \%$ FGF-2 inactivation. Dextran $(20 \mathrm{mg} / \mathrm{mL})$ almost completely protected FGF-2 activity up to $51^{\circ} \mathrm{C}$ and partially protected it at $58^{\circ} \mathrm{C}$ and $65^{\circ} \mathrm{C}$. On the other hand, LMW-H with dextran and LMW-H/P NPs with dextran showed greater protective effects against FGF-2 activity in heat treatment up to $65^{\circ} \mathrm{C}$.

LMW-H with dextran, dextran, and LMW-H/P NPs with dextran were able to protect inactivation of FGF-2 after trypsin treatment, while activity was lost in controls (Figure 7). In the presence of trypsin, the biological half-life of $10 \mathrm{ng} / \mathrm{mL}$ FGF2 with LMW-H with dextran, dextran and LMW-H/P NPs with dextran was about $>120 \mathrm{~min}, 80 \mathrm{~min}$, and $>120 \mathrm{~min}$, respectively (with control (non) $=20 \mathrm{~min}$ ). Thus, LMW-H/P NPs protects FGF-2 from inactivating treatments, similar to LMW-H/P MPs. ${ }^{19}$

\section{Discussion}

PECs are formed by electrostatic interactions between positively and negatively charged polymers. ${ }^{8}$ Basic protamine molecules complexed with acidic molecules (eg, LMW-H) form microparticles through ionic interactions.

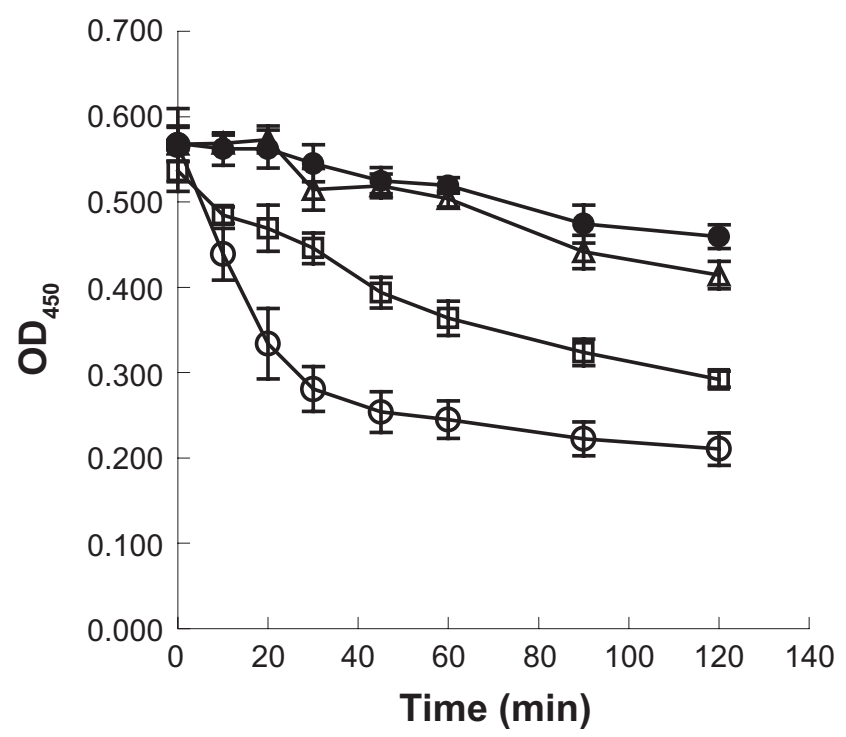

Figure 7 Protective effects of LMW-H/P NPs on bioactivity of trypsin-treated FGF-2. Stock solutions (10 $\mu \mathrm{g} / \mathrm{mL}$ FGF-2 with $3.14 \mathrm{mg} / \mathrm{mL}$ LMW-H/P NPs with $20 \mathrm{mg} / \mathrm{mL}$ dextran (O), $1.6 \mathrm{mg} / \mathrm{mL} \mathrm{LMW}-\mathrm{H}$ with $20 \mathrm{mg} / \mathrm{mL}$ dextran $(\triangle), 20 \mathrm{mg} / \mathrm{mL}$ dextran alone $(\square)$ or control (non) $(\bigcirc)$ ) were treated with trypsin at $37^{\circ} \mathrm{C}$ for the indicated periods of time. After trypsinization, proteolysis was stopped by adding FBS, and inactivated FGF-2 in the stock solutions was diluted to $10 \mathrm{ng} / \mathrm{mL}$ with culture medium. HMVECs were cultured for 3 days using one of the prepared media, and data represent means \pm SD of quadruplicate determinations.

Abbreviations: FGF-2, fibroblast growth factor-2; HMVECs, human dermal microvascular endothelial cells; LMW-H, low-molecular-weight heparin; LMW-H/P, lowmolecular-weight heparin/protamine; NP(s), nanoparticle(s); SD, standard deviation. 
We previously reported FGF-2-containing LMW-H/P MPs, which are $2.93 \pm 1.11 \mu \mathrm{m}$ in diameter, and due to their size, FGF-2-containing LMW-H/P MPs can be easily injected. ${ }^{19}$ FGF-2-containing LMW-H/P MPs showed substantial induction of vascularization and fibrous tissue formation due to the gradual release of FGF-2 molecules from LMW-H/P MPs. ${ }^{19}$ However, LMW-H/P MPs are unstable; the particles irreversibly fuse and become larger $(>10 \mu \mathrm{m}$ in diameter) during long-term storage (1 week or longer). Furthermore, after LMW-H/P MPs are freeze-dried, cotton-like materials are produced, and these do not dissolve in water. In this study, we established a method for preparing stable LMW-H/P NPs (about $100 \mathrm{~nm}$ in diameter), as well as stable LMW-H/P MPs $(2.93 \pm 1.11 \mu \mathrm{m}$ in diameter $)$, that maintained their solubility after lyophilization. Furthermore, the size of the generated particles (from about $100 \mathrm{~nm}$ to about $3 \mu \mathrm{m}$ ) could be controlled by dilution of the LMW-H and protamine solutions.

It is considered that whether LMW-H/P complexes form single nanoscale particles or microscale aggregates is dependent on concentrations of LMW-H and protamine in the pre-reaction solution. ${ }^{22}$ Polymer chains of both LMW-H and protamine have a number of reactive sites to countermolecules, and multiple polymer chains were involved in one LMW-H/P particle. Higher aggregation (MPs) was formed when higher concentration of both polymers was applied. The typical case derived from the high aggregation was observed in the mixture with nondiluted LMW-H and protamine. Because irreversible crosslinking simultaneously occurred between a large number of both LMW-H and protamine chains, strict size distribution of LMW-H/P MPs got out of control. Despite the difficulty of size distribution control of LMW-H/P MPs, it should be noted that any problems did not exist in the repeatability of the experiments using LMW-H/P MPs studied to date. ${ }^{19}$ On the other hand, in 20-fold and more diluted systems, only nanoscale particles were formed. And SEM of 10-fold diluted system showed that the products were a mixture of aggregations (MPs) and NPs.

When nondiluted protamine $(10 \mathrm{mg} / \mathrm{ml})$ was added drop by drop to nondiluted LMW-H $(6.4 \mathrm{mg} / \mathrm{ml})$ at a ratio of $3: 7$ (vol:vol), LMW-H/P MPs were generated (Figure 2). As described above, LMW-H/P MPs were stabilized by addition of $5 \mathrm{mg} / \mathrm{mL}$ dextran, and the freeze-dried powder of LMWH/P MPs and dextran easily dissolved in water, PBS and various culture media. Microscopic observations showed that the re-dissolved LMW-H/P MPs in solution were identical to those before lyophilization. Furthermore, FGF-2-containing
LMW-H/P MPs stabilized with dextran showed the same induction of vascularization and fibrous tissue formation due to the gradual release of FGF-2 molecules, as reported previously. ${ }^{19}$

There are some advantages in nanoparticles $(<200 \mathrm{~nm})$ as a drug carrier, as compared with microparticles $(>1 \mu \mathrm{m})$; (i) LMW-H/P NPs containing drugs may be administered intravenously, but LMW-H/P MPs may not, due to the higher risk of causing embolism by MPs because larger sizes of MPs are identical to that of red blood cells, the MPs are easily aggregated, and the MPs adhere to the wall of blood vessels, (ii) LMW-H/P NPs as a drug carrier may be endermically administered, but LMW-H/P MPs are too large, ${ }^{23,24}$ and (iii) LMW-H/P NPs diffuse into a relatively large area, but LMW-H/P MPs do not. Therefore, we tried to prepare stable LMW-H/P NPs in this study. When 20 -fold diluted protamine $(0.5 \mathrm{mg} / \mathrm{mL})$ was added drop by drop to 20 -fold diluted LMW-H $(0.32 \mathrm{mg} / \mathrm{mL})$ at a ratio of 3:7 (vol:vol), LMW-H/P NPs (112.5 $\pm 46.5 \mathrm{~nm}$ in diameter) were generated (Figure 4), and no microparticles $(>1 \mu \mathrm{m}$ in diameter) were observed in the mixture. The generated nanoparticles were also stabilized by adding dextran $(2 \mathrm{mg} / \mathrm{ml})$ and maintained their solubility after lyophilization.

FGF-2 is known to bind to heparin and LMW-H with high affinity $\left(\mathrm{K}_{\mathrm{d}}\right.$ of $\left.8.6 \times 10^{-9} \mathrm{M}\right){ }^{18,25}$ The polysaccharides also prolong the biological half-life of FGF-2 activity, and protect FGF-2 from heat, acid and proteolytic inactivation at concentrations up to $3 \mu \mathrm{g} / \mathrm{mL} .{ }^{18} \mathrm{LMW}-\mathrm{H} / \mathrm{P}$ MPs also have a high affinity for FGF-2 $\left(\mathrm{K}_{\mathrm{d}}=2.4 \times 10^{-9} \mathrm{M}\right),{ }^{19}$ and interaction between FGF-2 and LMW-H/P NPs substantially prolongs the biological half-life of FGF-2. LMW-H/P NPs also effectively protected FGF-2 against heat inactivation and trypsin degradation. The results demonstrated that FGF-2 molecules interact with, and are stabilized by LMW-H/P NPs, and that the FGF-2 molecules incorporated into the LMW-H/P NPs would be gradually released upon diffusion and biodegradation of the nanoparticles in vivo.

Heparinoids, including heparin and LMW-H, are known to bind cytokines such as FGFs, hepatocyte growth factor (HGF), vascular endothelial growth factor (VEGF), heparin-binding epidermal growth factor (HBEGF), plateletderived growth factor (PDGF), transforming growth factor- $\beta$ (TGF- $\beta$ ), GM-CSF, interleukins (ie, IL-1, IL-2, IL-3, IL-4, IL-6, IL-7, and IL-8), interferon- $\gamma$ and macrophage inflammatory protein-1 (MIP-1). ${ }^{26,27}$ LMW-H/P NPs can therefore be applied to such heparin-binding cytokines as a nanocarrier for drug delivery. 


\section{Conclusion}

In the present work, we established a methodology to prepare stable LMW-H/P NPs, and evaluated the effects of FGF2-containing LMW-H/P NPs on the protection of FGF-2 activity from heat and proteolytic inactivation. The results presented in this study indicate that LMW-H/P NPs may serve as an effective nanocarrier for various heparin-binding cytokines, including FGF-2, particularly in the local application of heparin-binding cytokines.

\section{Disclosures}

The authors report no conflicts of interest in this work.

\section{References}

1. Dautzenberg H, Hartmann J, Grunewald S, Brand F. Stoichiometry and structure of polyelectrolyte complex particles in diluted solution. Ber Bunsenges Phys Chem. 1996;100(6):1024-1032.

2. Wassmer KH, Schroeder U, Horn D. Characterization and detection of polyanions by direct polyelectrolyte titration. Makromol Chem. 1991;192(3):553-565.

3. Dragan S, Cristea M, Luca C, Simionescu BC. Polyelectrolyte complex. I: Synthesis and characterization of some insoluble polyanion-polycation complexes. J Polym Sci A. 1996;34(17):3487-3495.

4. Nordmeier E, Beyer P. Nonstoichiometric polyelectrolyte complexes: A mathematical model and some experimental results. J Polym Sci Pol Phys. 1999;37(4):335-348.

5. Park JM, Muhoberac BB, Dubin PL, Xia J. Effect of protein charge heterogeneity in protein-polyelectrolyte complexation. Macromolecules. 1992;25(1):290-295.

6. Mattison KW, Dubin PL, Brittain IJ. Complex formation between bovine serum albumin and strong polyelectrolytes: Effect of polymer charge density. J Phys Chem B. 1998;102(19):3830-3836.

7. Holappa S, Andersson T, Kantonen L, Plattner P, Tenhu H. Soluble polyelectrolyte complexes composed of poly (ethylene oxide)-blockpoly (sodium methacrylate) and poly (methacryloyloxyethyl trimethylammonium chloride). Polymer. 2003;44(26):7907-7916.

8. Webster L, Huglin MB, Robb ID. Complex formation between polyelectrolytes in dilute aqueous solution. Polymer. 1997;38(6):1373-1380.

9. Hashimoto M, Koyama Y, Sato T. In vitro gene delivery by pDNA/ chitosan complexes coated with anionic PEG derivatives that have a sugar side chain. Chem Lett. 2008;37(3):266-267.

10. Denuziere A, Ferrier D, Domard A. Chitosan-chondroitin sulfate and chitosan-hyaluronate polyelectrolyte complexes. Physico-chemical aspects. Carbohydr Polym. 1996;29(4):317-323.
11. Ishihara M, Ono K. Structure and function of heparin and heparan sulfate: heparinoid library and modification of FGF-activities. Trends Glycosci Glycotechnol. 1998;10(52):223-233.

12. Salmivirta M, Lidhold K, Lindahl U. Heparan sulfate: a piece of information. FASEB J. 1996;10(11):1270-1279.

13. Lindahl U, Lidholt K, Spillmann D, Kjellen L. More to "heparin" than anti-coagulation. Thromb Res. 1994;75(1):1-32.

14. Hirsh J, Warkentin TE, Shaughnessy SG, et al. Heparin and lowmolecular heparin, mechanisms of action, phormacokinetics, dosing, monitoring, efficacy, and safety. Chest. 2001;119(2 Suppl):64S-94S.

15. Wolzt M, Wetermann A, Nieszpaur-Los M, et al. Studies on the neutralizing effects of protamine on unfractionated and low molecular weight heparin $\left(\right.$ Fragmin $\left.^{\circledR}\right)$ at the site of activation of the coagulation system in man. Thromb Haemost. 1995;73(3):439-443.

16. Pan M, Lezo JS, Medina A, et al. In-laboratory removal of femoral sheath following protamine administration in patients having intracoronary stent implantation. Am J Cardiol. 1997;80(10):1336-1338.

17. Fujita M, Ishihara M, Shimizu M, et al. Vascularization in vivo caused by the controlled release of fibroblast growth factor- 2 from an injectable chitosan/non-anticoagulant heparin hydrogel. Biomaterials. 2004;25(4):699-706.

18. Nakamura S, Nambu M, Kishimoto S, et al. Effect of controlled release of fibroblast growth factor-2 from chitosan/fucoidan micro complex hydrogel on in vitro and in vivo vascularization. J Biomed Mater Res A. 2008;85(3):619-627.

19. Nakamura S, Kanatani Y, Kishimoto S, et al. Controlled release of FGF-2 using fragmin/protamine microparticles and effect on neovascularization. J Biomed Mater Res A. 2009;91(3):814-823.

20. Nakamura S, Ishihara M, Obara $K$, et al. Controlled release of fibroblast growth factor-2 from an injectable 6-O-desulfated heparin hydrogel and subsequent effect on in vivo vascularization. J Biomed Mater Res A. 2006;78(2):364-371.

21. Gospodarowicz D, Cheng J. Heparin protects basic and acidic FGF from inactivation. J Cell Physiol. 1986;128(3):475-484.

22. Koetz J, Kosmella S. Polyelectrolytes and Nanoparticles. New York, NY: Springer; 2007.

23. Tinkle SS, Antonini JM, Rich BA, et al. Skin as a route of exposure and sensitization in chronic beryllium disease. Environ Health Perspect. 2003;111(9):1202-1208.

24. Verma DD, Verma S, Blume G, Fahr A. Particle size of liposomes influences dermal delivery of substances into skin. Int J Pharm. 2003;258(1-2):141-151.

25. Masuoka K, Ishihara M, Asazuma T, et al. The interaction of chitosan with fibroblast growth factor-2 and its protection from inactivation. Biomaterials. 2005;26(16):3277-3284.

26. Kishimoto S, Nakamura S, Hattori H, et al. Human stem cell factor (SCF) is a heparin-binding cytokine. J Biochem. 2009;145(3):275-278.

27. Ono K, Hattori H, Takeshita S, Kurita A, Ishihara M. Structural features in heparin that interact with VEGF165 and modulate its biological activity. Glycobiology. 1999;9(7):705-711.
International Journal of Nanomedicine

\section{Publish your work in this journal}

The International Journal of Nanomedicine is an international, peerreviewed journal focusing on the application of nanotechnology in diagnostics, therapeutics, and drug delivery systems throughout the biomedical field. This journal is indexed on PubMed Central, MedLine, CAS, SciSearch $\AA$, Current Contents ${ }^{\circledR} /$ Clinical Medicine,

\section{Dovepress}

Journal Citation Reports/Science Edition, EMBase, Scopus and the Elsevier Bibliographic databases. The manuscript management system is completely online and includes a very quick and fair peer-review system, which is all easy to use. Visit http://www.dovepress.com/ testimonials.php to read real quotes from published authors. 